\title{
WITHDRAWAL OF ENDOGENOUS SYMPATHETIC DRIVE LOWERS BLOOD PRESSURE IN PRIMARY ALDOSTERONISM
}

\author{
M. G. NICHOLLS, S. JULIUS AND A. J. ZWEIFLER \\ Division of Hypertension, Department of Internal Medicine, University of Michigan \\ Medical School, Ann Arbor, USA
}

(Received 16 February 1981; accepted 13 April 1981)

\begin{abstract}
SUMMARY
We were able to observe the effect of withdrawal of endogenous sympathetic drive in a hypertensive patient with an aldosterone-secreting adrenal adenoma. Acute stimulation of both carotid sinus nerves lowered blood pressure to normotensive or hypotensive levels by reducing peripheral resistance. When chronic carotid sinus nerve stimulation was discontinued, peripheral resistance and blood pressure increased. These data suggest that the sympathetic nervous system is important in the maintenance of hypertension in established primary aldosteronism.
\end{abstract}

The pathogenesis of the hypertension in primary aldosteronism has intrigued and baffled researchers. Whereas there is evidence that the sympathetic nervous system may play a vital role in the development and maintenance of elevated pressures in one animal model of mineralocorticoid hypertension (DOCA-salt hypertension in rats), the possibility that a neurogenic component is important in the hypertension of human primary aldosteronism has received scant study. We had the unique opportunity to document blood pressure and haemodynamic responses to withdrawal of endogenous sympathetic drive in a patient with primary aldosteronism. Our data show that sympathetic drive is not suppressed and suggest that sympathetic nervous activity contributes to the hypertension of primary aldosteronism.

\section{CASE REPORT}

The patient, a 47-year-old white male was first observed to have elevated blood pressure $(150 / 90 \mathrm{~mm} \mathrm{Hg})$ in 1948 at 16 years of age. Drug treatment was initiated at 34 years when severe hypertension was documented $(200 / 120 \mathrm{~mm} \mathrm{Hg})$. Blood pressure control was poor despite multiple therapeutic regimes, and drug-induced side effects were prominent. He complained of intermittent muscle weakness, and hypokalaemia $(2.3-3.4 \mathrm{mmol} / 1)$ was

Correspondence: Dr M. G. Nicholls, Department of Endocrinology, Princess Margaret Hospital, Christchurch, New Zealand.

0300-0664/81/0900-0253\$02.00 C 1981 Blackwell Scientific Publications 
noted on a number of occasions, usually during thiazide treatment. Primary aldosteronism was suspected but plasma renin results obtained in 1972 were difficult to interpret.

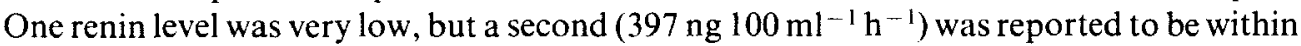
normal limits. The second sample, however, was obtained while the patient's blood pressure was very high $(220 / 140 \mathrm{~mm} \mathrm{Hg})$, and the renin-angiotensin system was being stimulated by the combination of a low sodium diet ( $10 \mathrm{mmol} /$ day), upright body posture, and thiazide and hydralazine treatment. Aldosterone measurements were not obtained at this time.

In view of the uncontrolled hypertension, the drug-related side effects, and in the absence of a definitive diagnosis of primary aldosteronism, consideration was given to attempt blood pressure control with chronic carotid sinus nerve stimulation. The experimental nature of the procedure was fully explained to the patient, and his consent was obtained. Ethical Committee approval was given for this procedure in otherwise uncontrollable hypertension. In February 1972, a Medtronic Barostat ${ }^{\circledR}$ bilateral carotid sinus nerve stimulator was implanted (Schwartzet al., 1967). Over the subsequent 6 years, blood pressure levels were considerably lowered (Fig. 1). Prolonged normalization of pressure was not possible only because the patient experienced an unpleasant sensation in the throat at high baropacer settings, thus diuretic (and supplementary potassium) therapy was required along with a low level of carotid sinus nerve stimulation. Between 1972 and 1978, withdrawal of baropacer stimulation invariably resulted in the return of severe hypertension (Fig. 1). When the baropacer setting was temporarily increased, blood pressure regularly fell to hypotensive levels (less than $110 / 70 \mathrm{~mm} \mathrm{Hg}$, see Fig. 2).

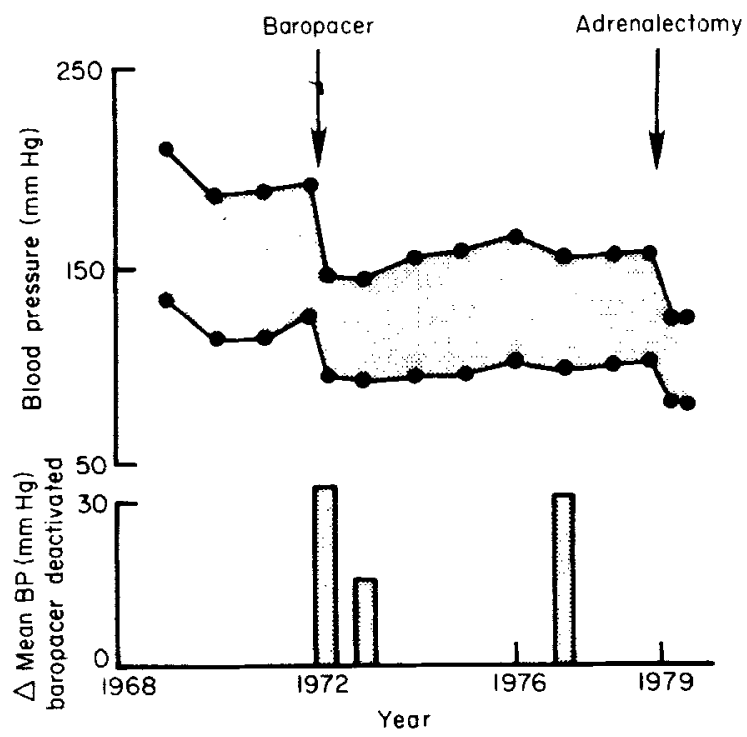

Fig. 1. Blood pressure responses to bilateral carotid nerve stimulation (baropacer), and to unilateral adrenalectomy in a patient with primary aldosteronism. After 1970. blood pressure levels shown are the mean of at least three readings. Multiple combined drug regimes were used prior to baropacer insertion, diuretic and potassium treatment was generally required during the period of baropacer stimulation, and a combination of diuretic and alpha methyldopa therapy was exhibited after adrenalectomy. The lower panel represents the rise in mean blood pressure when chronic carotid sinus nerve stimulation was temporarily terminated. 

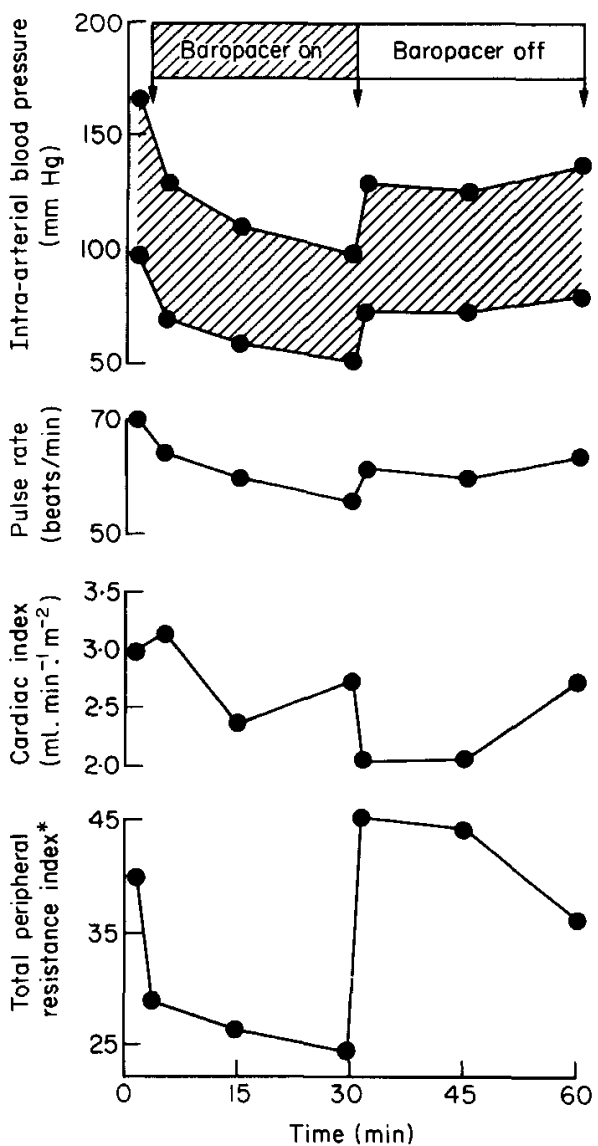

Fig. 2. Haemodynamic responses to bilateral carotid sinus nerve stimulation in a patient with primary aldosteronism during thiazide diuretic and supplemental potassium therapy. The patient was supine during this study. Cardiac output was measured following the injection of indocyanine green. ${ }^{*}$ Resistance index is in arbitrary units (= mean arterial pressure/cardiac index).

Haemodynamic studies performed in 1972 (Fig. 2), and repeated in 1973, showed that baropacer stimulation lowered supine blood pressure primarily by reducing peripheral resistance, although pulse rate and cardiac index also fell somewhat. These changes were reversed when the baropacer was switched off (Fig. 2).

An intermittent electrical malfunction developed from 1975 which necessitated an increase in antihypertensive medication. However, when functioning correctly, baropacer stimulation continued to reduce blood pressure, often to hypotensive levels.

In 1978, the baropacer was switched off, medications were stopped, and treatment with the oral converting enzyme inhibitor captopril ( $150 \mathrm{mg}$ three times daily) was initiated in the Clinical Research Center at the University of Michigan Hospital. Blood pressure rose to $180 / 125 \mathrm{~mm} \mathrm{Hg}$. Addition of hydrochlorothiazide had little effect on the blood pressure but serum potassium fell to $1.9 \mathrm{mmol} / 1$. The diagnosis of primary aldosteronism was again entertained, and was confirmed when plasma renin activity (Haber et al., 1969) and angiotensin II levels (Nicholls \& Espiner, 1976) were found to be low, and serum aldosterone levels (Antunes et al., 1976) did not decline during a high sodium intake 
Table 1. Plasma hormone and electrolyte indices $(1978)^{*}$

\begin{tabular}{|c|c|c|c|c|c|}
\hline & \multirow[b]{2}{*}{$\begin{array}{c}\text { PRA } \\
\left(\mathrm{ng} \cdot \mathrm{ml}^{-1} \cdot \mathrm{h}^{-1}\right)\end{array}$} & \multirow[b]{2}{*}{$\begin{array}{l}\text { Angiotensin II } \\
(\mathrm{pg} / \mathrm{ml})\end{array}$} & \multirow[b]{2}{*}{$\begin{array}{l}\text { Aldosterone } \\
(\mathrm{ng} / 100 \mathrm{ml})\end{array}$} & \multicolumn{2}{|c|}{ Serum } \\
\hline & & & & $\begin{array}{l}\text { Sodium } \\
(\mathrm{mmol} / \mathrm{l})\end{array}$ & $\begin{array}{c}\text { Potassium } \\
(\mathrm{mmol} / \mathrm{l})\end{array}$ \\
\hline \multicolumn{6}{|c|}{$\begin{array}{l}3 \text { days high sodium diet: } \\
\text { ( } \mathrm{Na} 200 \mathrm{mmmol} / \mathrm{day} \text {, } \\
\mathrm{K} 100 \mathrm{mmol} / \mathrm{day} \text { ) }\end{array}$} \\
\hline Supine & $<0.01$ & $<5$ & $36 \cdot 2$ & 148 & $2 \cdot 8$ \\
\hline Upright $2 \mathrm{~h}$ & $<0.01$ & $<5$ & $27 \cdot 5$ & 142 & $3 \cdot 2$ \\
\hline Upright $4 \mathrm{~h}$ & $<0.01$ & $<5$ & $27 \cdot 6$ & 143 & $3 \cdot 1$ \\
\hline \multicolumn{6}{|c|}{$\begin{array}{l}4 \text { days low sodium diet: } \\
\text { ( Na } 10 \mathrm{mmol} / \text { day, } \\
\text { K } 100 \mathrm{mmol} / \mathrm{day})\end{array}$} \\
\hline Supine & 0.08 & $<5$ & $26 \cdot 4$ & 145 & $3 \cdot 4$ \\
\hline Upright $2 \mathrm{~h}$ & 0.13 & $<5$ & $27 \cdot 1$ & 142 & $3 \cdot 7$ \\
\hline Upright $4 \mathrm{~h}$ & 0.04 & $<5$ & $23 \cdot 7$ & 142 & $3 \cdot 7$ \\
\hline
\end{tabular}

* The patient was receiving supplemental oral potassium as the only medication for 2 weeks before studies.

Conversion to SI units: PRA $1 \mathrm{ng} \cdot \mathrm{ml}^{-1} \cdot \mathrm{h}^{-1}=0 \cdot 77 \mathrm{nmol} \cdot \mathrm{l}^{-1} \cdot \mathrm{h}^{-1}$. Angiotensin II $\mathrm{l}$ $\mathrm{pg} / \mathrm{ml}=0.95 \mathrm{pmol} / \mathrm{l}$. Aldosterone $1 \mathrm{ng} / 100 \mathrm{ml}=27.8 \mathrm{pmol} / \mathrm{l}$.

(Table 1). Urine aldosterone excretion (Bayard et al., 1970) measured during the high sodium intake was elevated at $82.5 \mu \mathrm{g} / 24 \mathrm{~h}$ (normal $2-15 \mu \mathrm{g} / 24 \mathrm{~h}$ ).

Bilateral adrenal vein sampling and venography, together with iodocholesterol adrenal scanning suggested a single adenoma on the left, which was confirmed at unilateral adrenalectomy in January 1979. Two months after surgery urine aldosterone was normal $(11.2 \mu \mathrm{g} / 24 \mathrm{~h})$, as was his ambulatory plasma renin $\left(2.5 \mathrm{ng} . \mathrm{ml}^{-1} \mathrm{~h}^{-1}\right.$, urine sodium 127 $\mathrm{mmol} / 24 \mathrm{~h}$ ). Although his blood pressure was slightly elevated at this time $(140 / 88-168 / 104 \mathrm{~mm} \mathrm{Hg}$ ), it was considerably lower than in previous years (Fig. I) and was returned to normal by hydrochlorothiazide and $\alpha$ methyldopa therapy. The patient's vigour and well-being were dramatically improved following unilateral adrenalectomy.

\section{DISCUSSION}

The pathogenesis of the hypertension in primary aldosteronism is unclear. It is probable that there is a complex interplay of a number of mechanisms, and that these factors differ in importance at the developmental and the maintenance phases of the hypertension.

Involvement of the sympathetic nervous system in one model of mineralocorticoid hypertension, the DOCA-salt uninephrectomized rat, has been extensively studied. Although interpretation of this literature is open to debate (Louis et al., 1970), the data strongly suggest an important role for the sympathetic nervous system in this type of hypertension. Specifically, studies in this model have documented an increase in norepinephrine turnover in many organs including the heart (de Champlain et al., 1969), raised circulating norpinephrine levels (Reid et al., 1975; de Champlain et al., 1976), enhanced pressor responsiveness to administered norepinephrine (Beilin et al., 1970), 
increased sympatho-adrenal activity (Grobecker et al., 1976) and return of blood pressure to normal following either destruction of central catecholinergic neurons (Reid et al., 1975) or combined chemical sympathectomy and bilateral adrenalectomy (de Champlain \& van Ameringen, 1972).

A possible pathogenic role for the sympathetic system in human mineralocorticoid hypertension has received less attention. During the developmental phase of the hypertension, pulse rate is slowed (Nicholls et al., 1979) and plasma norepinephrine levels fall (Distler et al., 1979), perhaps reflecting a reduction of sympathetic drive at this initial stage. The hypertension of established primary aldosteronism may be hyperkinetic (Tarazi et al., 1973), which would be consistent with there being an active sympathetic nervous system at this phase. On the contrary, there are data suggestive of a reduced adrenergic state in primary aldosteronism (Biglieri \& McIlroy, 1966; Distler et al., 1970).

The present case study shows that withdrawal of endogenous sympathetic drive by stimulation of a physiological pathway (the carotid sinus baroreceptor nerves) is capable of returning blood pressure to normal in a patient with established primary aldosteronism. Although anecdotal, this finding has important implications. First, it is evident that unlike the renin-angiotensin system, sympathetic nervous activity was not completely suppressed in our patient. Secondly, in that withdrawal of endogenous sympathetic tone was capable of lowering blood pressure into and below normotensive levels, it is likely that the sympathetic nervous system at least contributed to the maintenance of the hypertension.

The hypertension in established primary aldosteronism is maintained largely by a high peripheral resistance (Tarazi et al., 1973). In the present case, withdrawal of endogenous sympathetic drive returned blood pressure to normal primarily by reducing peripheral resistance. Thus, sympathetic nervous system activity was contributing to the underlying haemodynamic abnormality, i.e. the elevated vascular resistance.

The present data do not allow the conclusion that sympathetic nervous system activity is increased in established primary aldosteronism. Nevertheless, even a 'normal' level of sympathetic function may be important along with other factors, such as hypervolaemia, in determining the degree of hypertension in these patients.

\section{ACKNOWLEDGEMENTS}

The patient was studied in the Clinical Research Center, University of Michigan Medical School, under USPHS grant no. 5-MO1-RR-42. We are grateful to Paula Gilson for typing the manuscript.

\section{REFERENCES}

ANTUNES, J.R., DALE, S.L. \& MELBY, J.C. (1976) Simplified radioimmunoassay for aldosterone using antisera to aldosterone- $\gamma$-lactone. Steroids, 28, 621-630.

Bayard, F.. Beitins, I.Z., Kowarski, A.\& Migeon, C.J. (1970) Measurement of aldosterone secretion rate by radioimmunoassay. Journal of Clinical Endocrinology, 31, 507-510.

BeILIN, L.J., W ADE, D.N., HoNOUR, A.J. \& COLE, T.J. (1970) Vascular hyper-reactivity with sodium loading and with desoxycorticosterone induced hypertension in the rat. Clinical Science, 39, 793-810.

BIGLIERI, E.G. \& MClLroy, M.B. (1966) Abnormalities of renal function and circulatory reflexes in primary aldosteronism. Circulation, 33, 78-86.

DE Champlain, J.\& van Ameringen, M.R. ( 1972) Regulation of blood pressure by sympathetic nerve fibres and adrenal medulla in normotensive and hypertensive rats. Circulation Research, 31, 617-628.

de Champlain, J., KrakofF, L. \& AXELrod, J. (1969) Inter-relationships of sodium intake, hypertension, and 
norepinephrine storage in the rat. Circulation Research, $24 \& 25$, Suppl. 1, 75-92.

de Champlain, J., Farley, L., Cousineau, D. \& van Ameringen, M.R. (1976) Circulating catecholamine levels in human and experimental hypertension. Circulation Research, 38, 109-114.

Distler, A., Barth, Ch., Liebau, H., Vecsei, P. \& Wolff, H.P. (1970) The effect of tyramine, noradrenaline, and angiotensin on the blood pressure in hypertensive patients with aldosteronism and low plasma renin. European Journal of Clinical Investigation, 1, 196-203.

Distler, A., Philipp, T., Lüth, B. \& Wucherer, G. (1979) Studies on the mechanism of mineralocorticoidinduced blood pressure increase in man. Clinical Science; 57, 303s-305s.

Grobecker, H., SaAvedra, J.M., Roizen, M.F., Weise, V., Kopin, I.J. \& Axelrod, J. (1976) Peripheral and central catecholaminergic neurons in genetic and experimental hypertension in rats. Clinical Science and Molecular Medicine. 51, 377s-380s.

Haber, E., Kolrner, T., Page, L.B.. Kliman, B. \& Purnode. A. (1969) Application of a radioimmunoassay for angiotensin I to the physiologic measurement of plasma renin activity in normal human subjects. Journal of Clinical Endocrinology, 29, 1349-1355.

Louis. W.J., Krauss, K.R., KopIn, I.J. \& Sjoerdsma, A. (1970) Catecholamine metabolism in hypertensive rats. Circulation Research, 27, 589-594.

Nicholls, M.G. \& Espinfr, E.A. (1976) A sensitive, rapid radioimmunoassay for angiotensin II. New Zealand Medical Journal, 83, 399-403.

Nicholls, M.G., Ramsay, L.E., Boddy, K., Fraser, R., Morton, J.J. \& Robertson, J.I.S. (1979) Mineralocorticoid-induced blood pressure, electrolyte, and hormone changes, and reversal with spironolactone in healthy men. Metabolism, 28, 584-593.

Reid, J.L., Ziviv, J.A. \& KoPIN, I.J. (1975) Central and peripheral adrenergic mechanisms in the development of deoxycorticosterone-saline hypertension in rats. Circulation Research, 37, 569-579.

SChwartZ, S.I.. Griffith, L.S.C., Neistadt, A. \& HaGfors, N. (1967) Chronic carotid sinus nerve stimulation in the treatment of essential hypertension. American Journal of Surgery, 114, 5-15.

Tarazi, R.C.. IBrahim, M.M. Bravo E.L. \& Dustan, H.P. (1973) Hemodynamic characteristics of primary aldosteronism. New England Journal of Medicine. 289, 1330-1335. 